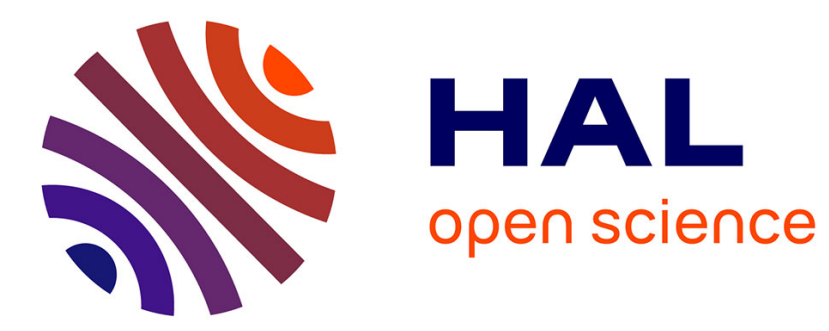

\title{
Omental Flap for Hepatic Artery Coverage During Liver Transplantation
}

Fabrizio Panaro, Hassan Bouyabrine, Jean-Pierre Carabalona, Stéphanie Nougaret, Boris Jung, Georges Philippe Pageaux, Francis Navarro

\section{To cite this version:}

Fabrizio Panaro, Hassan Bouyabrine, Jean-Pierre Carabalona, Stéphanie Nougaret, Boris Jung, et al.. Omental Flap for Hepatic Artery Coverage During Liver Transplantation. Journal of Gastrointestinal Surgery, 2014, 18 (8), pp.1518-1522. 10.1007/s11605-014-2484-6 . hal-02550727

\section{HAL Id: hal-02550727 \\ https://hal.umontpellier.fr/hal-02550727}

Submitted on 22 Apr 2020

HAL is a multi-disciplinary open access archive for the deposit and dissemination of scientific research documents, whether they are published or not. The documents may come from teaching and research institutions in France or abroad, or from public or private research centers.
L'archive ouverte pluridisciplinaire HAL, est destinée au dépôt et à la diffusion de documents scientifiques de niveau recherche, publiés ou non, émanant des établissements d'enseignement et de recherche français ou étrangers, des laboratoires publics ou privés. 


\title{
Omental Flap for Hepatic Artery Coverage During Liver Transplantation
}

\author{
Fabrizio Panaro • Hassan Bouyabrine • \\ Jean-Pierre Carabalona • Stephanie Nougaret • \\ Boris Jung • Georges Philippe Pageaux • Francis Navarro
}

\begin{abstract}
In 1994, a technique of omental flap interposition to cover the celiac and mesenteric vessels after pancreaticoduodenectomy was described. It aimed to isolate the pancreatic anastomosis from the vessels dissected during pancreaticoduodenectomy. In liver transplantation (LT), the omental flap was initially used to reduce the risk of hepatic artery (HA) kinking. Currently, we use this technique to cover the dissected HA, reducing the consequences of postoperative biliary fistula (BF), particularly the risk of postoperative complications (thrombosis/bleeding). We describe this technique adding a simple modification consisting of covering the HA with an omental flap after completion of the biliary anastomosis. We performed LT with an omental flap to cover the HA vessels in $62(55 \%)$ of the 112 consecutive patients who underwent LT between January 2012 and July 2013. No postoperative deaths occurred. The rate of BF was $9.7 \%$ (six cases). In the omental flap series, no postoperative thrombosis, HA pseudoaneurysm, or complications occurred. In the six cases of BF, the dissected HAs were completely isolated from the biloma. This simple technique has no specific morbidity; it isolates the HA from the biliary anastomosis and therefore may reduce the risk of severe postoperative HA complications after LT.
\end{abstract}

Keywords Liver transplantation $\cdot$ Biliary fistula $\cdot$ Hepatic artery $\cdot$ Omental flap

\section{Introduction}

The various surgical techniques and/or the perioperative therapies described to decrease the rate of biliary fistula (BF) after

Fabrizio Panaro and Hassan Bouyabrine contributed equally to this work.

F. Panaro $\cdot$ H. Bouyabrine $\cdot$ J.-P. Carabalona $\cdot$ B. Jung $\cdot$

G. P. Pageaux $\cdot$ F. Navarro

Department of General and Liver/Pancreas Transplant Surgery,

School of Medicine, Hôpital Saint Eloi, University of Montpellier, 80

Avenue Augustin Fliche, 34295 Montpellier, Cedex 5, France

\section{S. Nougaret}

Department of Radiology, School of Medicine, Hôpital Saint Eloi, University of Montpellier, 80 avenue Augustin Fliche, 34295 Montpellier Cedex 5, France

\section{F. Panaro $(\bowtie)$}

Department of Surgery, Liver Transplant Unit, College of Medicine, Montpellier University Hospital, 80 Avenue Augustin Fliche, 34295 Montpellier Cedex 5, France

e-mail: f-panaro@chu-montpellier.fr liver transplantation (LT) did not have great efficacy. ${ }^{1} \mathrm{BF}$ is currently a cause of major morbidity after LT and still appears in $10-15 \%$ of cases. ${ }^{1,2}$ Furthermore, today, many LTs are performed using elderly donors and partial liver grafts (split liver, living donor), two factors which may increase the risk of BF. ${ }^{3}$

As these two factors cannot be modified, the decrease in the rate of $\mathrm{BF}$ is still a function of the surgeon experience and of the transplant center volume. ${ }^{3}$ Therefore, as BF after LT cannot be reduced, efforts are made to reduce the severe hepatic artery (HA) complications such as thrombosis or pseudoaneurysm. ${ }^{4}$ In this context, Moriura et al. ${ }^{5}$ described in 1994 a technique to cover the celiac trunk and mesenteric vessels after pancreaticoduodenectomy utilizing an omental flap, a technique which was recently updated. ${ }^{6-8}$

The purpose of this omental flap coverage was to isolate the pancreatic anastomosis from the vessels dissected during the pancreaticoduodenectomy and thus to decrease the rate of bleeding. ${ }^{9}$

The usage of an omental flap to decrease the risks of bile duct complications after liver transplantation has been reported. ${ }^{10}$ In the previously reported experience, the group performing the research rapped the omentum around the bile duct, with the idea of inducing a neovascularization that would have protected the anastomosis from ischemic damage. 
On the basis of these interesting results, we adopted the omental flap to cover the dissected vessels during LT since 2012, and here, we describe the technique.

\section{Technique}

Routinely, we perform LT with a standard technique as previously described. ${ }^{11}$ The vena cava reconstruction is performed using a piggyback technique, the portal vein reconstruction with an end-to-end anastomosis, and the $\mathrm{HA}$ reconstruction anastomosing the common graft HA (segment of the hepatic artery between the celiac trunk and the gastroduodenal artery) to the recipient common HA (junction with the gastroduodenal artery).

In about $15 \%$ of cases, a complex vascular reconstruction is required due to the presence of accessory arteries (right HA origin from the superior mesenteric artery).

After the graft revascularization, the biliary anastomosis is routinely performed between the graft hepatic duct (above the cystic duct) and the recipient choledochus (end-to-end fashion) with a 5/0 running and/or an interrupted resorbable suture (PDS ${ }^{\mathrm{TM}}$; Ethicon,
Johnson \& Johnson International (Belgium)) depending on the caliber of the anastomosis.

All transplantations were routinely performed by an experienced surgeon ( $>50$ liver transplantations) with $\times$ 2.5 magnification loupes for the small sutures (artery and bile duct). ${ }^{12}$

At the end of the anastomosis, we perform an omental flap by cutting the great omentum with a LigaSure device (LigaSure ${ }^{\mathrm{TM}}$, Covidien Energy (Ireland)) or with scissors after simple ligatures (3/0 Vicryl ${ }^{\mathrm{TM}}$; Ethicon, Johnson \& Johnson International (Belgium)). Additional hemostasis is made with bipolar forceps.

The omental flap is performed by sectioning the great omentum from the tip to the base at the level of the transverse colon.

We push the omental flap with a dissector behind the HA from the left to the right side, giving a harmonious curve to the HA, especially in the case of long arteries (accessory left HA origin from the left gastric artery) and/or in cases of vascular reconstruction (accessory right HA origin from the superior mesenteric artery). Then, with the tip of the flap (3-5 cm long), we cover the artery and the anastomosis (Figs. 1 and 2). We put two stitches into the omental graft (3/0 Vicryl ${ }^{\mathrm{TM}}$; Ethicon, Johnson \& Johnson International (Belgium)), fixing it (tip of the omental flap) to itself.
Fig. 1 a Omental flap pull behind the hepatic artery $(H A)$. b Omental flap $(O F)$ turned around (arrow) the hepatic artery. c Tip of the omental flap fixed with few stitches. $B D$ bile duct, $P V$ portal vein (behind the $\mathrm{BD}$ )
A

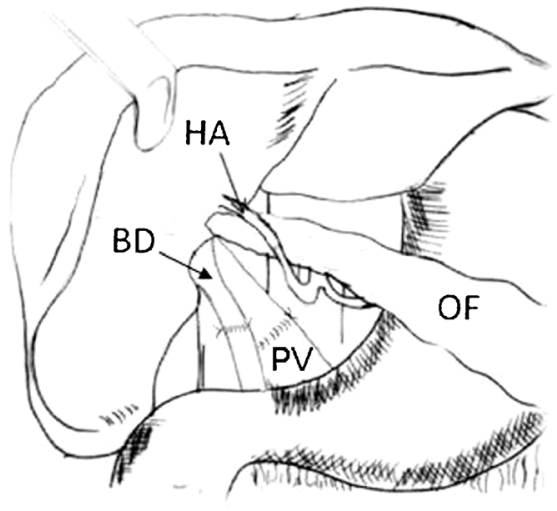

B

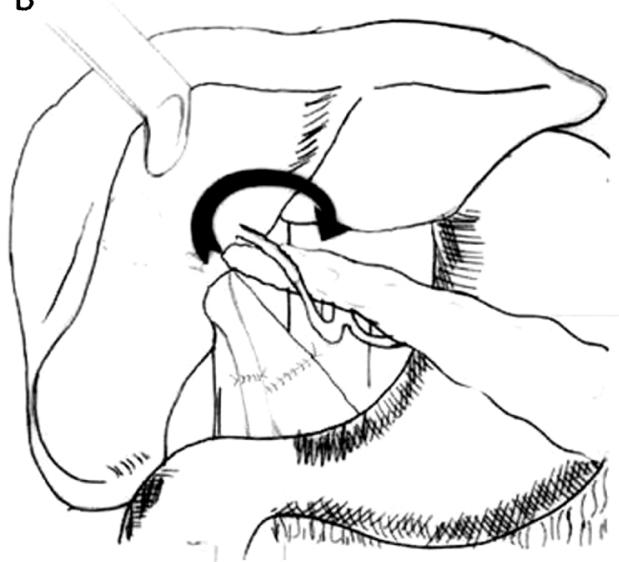

C

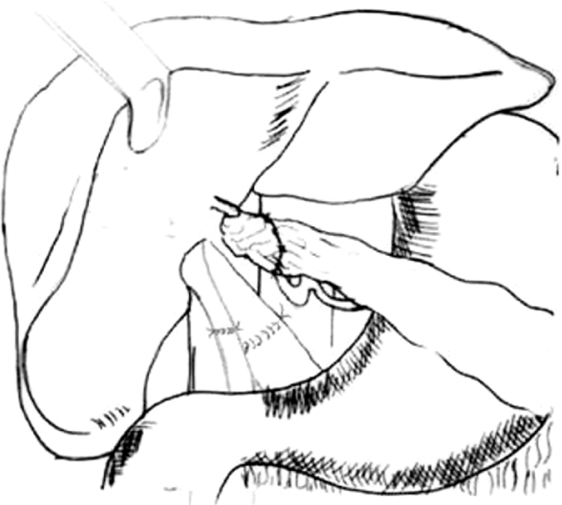



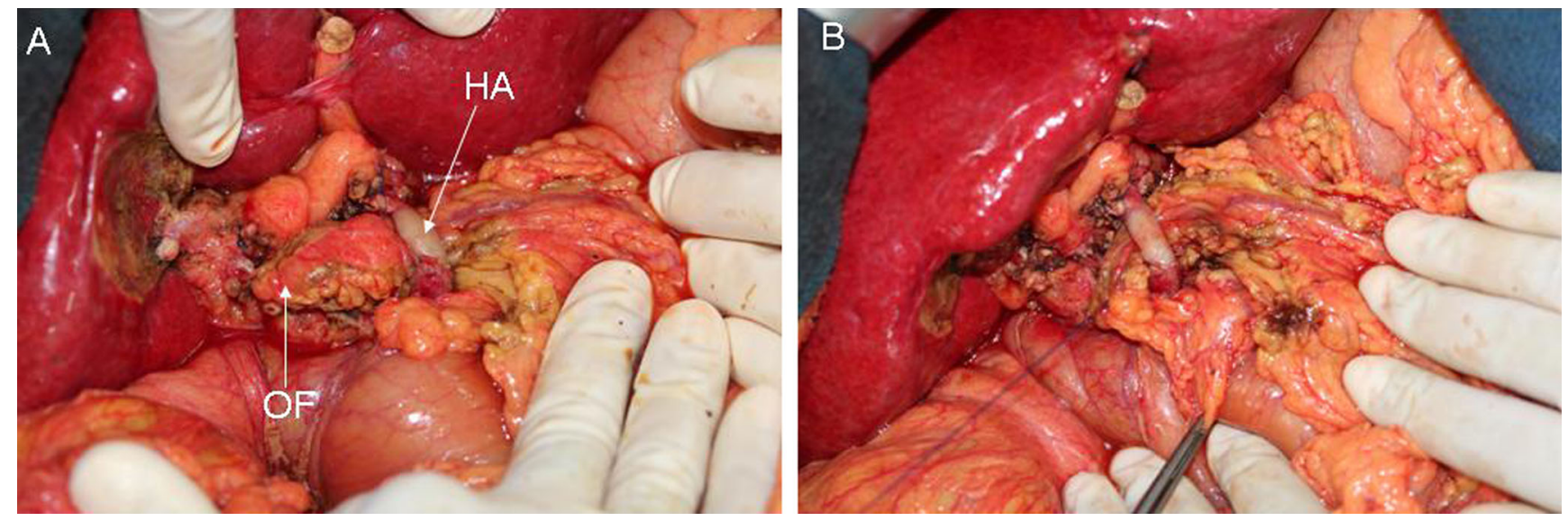

Fig. 2 Intraoperative view. a The omental flap $(O F)$ is passed behind the hepatic artery $(H A)$. b The omental flap is fixed with $3 / 0$ stitches

During this procedure, we verify to avoid any torsion of the flap that may cause poor vascularization or necrosis.

\section{Results}

This technique of omental flap coverage was performed in $62(55 \%)$ of the 112 consecutive patients who underwent LT between January 2012 and July 2013 in our center. In the other 50 patients, omentoplasty was not performed due to the surgeon policy practice (two out four surgeons in the division) $(n=42)$, either because the great omentum was previously utilized $(n=5)$ or the greater omentum was too short to be utilized $(n=$ 3). Patients' data are summarized in Table 1.

The mortality rate was 0 in the omental flap series and $8 \%$ (four patients died) in the non-omental flap group. Six patients $(9.7 \%)$ had a postoperative BF reported as a fluid collection (biloma) at imaging (ultrasound, CT scan, MRI) (Fig. 3).

All these patients were reoperated, and a Roux-en-Y hepaticojejunostomy was performed in all cases.

Table 1 Patients data

\begin{tabular}{llll}
\hline & $\begin{array}{l}\text { Omental } \\
\text { flap }(n=62)\end{array}$ & $\begin{array}{l}\text { Non-omental } \\
\text { flap }(n=50)\end{array}$ & $p$ value $^{\text {a }}$ \\
\hline $\begin{array}{l}\text { Recipient age, years } \\
\text { (median and range) }\end{array}$ & $54(32-67)$ & $56(18-70)$ & $\mathrm{NS}$ \\
$\begin{array}{l}\text { Gender (M/F) } \\
\begin{array}{l}\text { Donor age, years, } \\
(\text { median and range) }\end{array}\end{array}$ & $40 / 22$ & $32 / 18$ & $\mathrm{NS}$ \\
$\begin{array}{l}\text { BF, } n(\%) \\
\text { Artery complications, } n(\%)\end{array}$ & $0(0)$ & $44(20-84)$ & $\mathrm{NS}$ \\
\hline
\end{tabular}

$n$ number, $M$ male, $F$ female, $B F$ biliary fistula, $N S$ not significant

${ }^{\text {a }}$ Significant if $<0.05$

${ }^{\mathrm{b}}$ Two pseudoaneurysms (associated with bleeding) and two thromboses
Intraoperatively, the bile collection was isolated from the HA by the omental flap. No perioperative difficulties were encountered by the surgeons during the hepatic pedicle dissection.

Among the 50 patients who did not undergo omentoplasty, four $(8 \%)$ developed $\mathrm{BF}$, and four $(8 \%)$ developed HA complications (two pseudoaneurysm associated with bleeding and two thrombosis), whereas no complications were noticed in the omental flap series $[p=0.04,95 \%$ confidence interval $(-0.1579,-0.0021)]$.

All the BFs were treated by Roux-en-Y hepaticojejunostomy. The pseudoaneurysms manifested with a severe bleeding were successfully treated by inversed saphenous bypasses. The two thromboses were treated by a retransplantation after a surgical revascularization attempt (arterial thrombectomy and/or reanastomosis).

\section{Discussion}

Being independent of the transplant team, the LT had common phases (hepatectomy, vena cava anastomosis, portal anastomosis, hepatic artery anastomosis, and at the end, the bile duct reconstruction). However, each transplant team and each transplant surgeon had a routine technique to optimize the biliary reconstruction to reduce the risk of bile duct complications (stenosis and leak).

The technical details are difficult to evaluate. Furthermore, the analysis of our series cannot certify that the omental flap coverage is the only technique available to reduce the rate of hepatic artery complications, because other parameters must be considered (donor age, recipient MELD, bile duct diameter, bile duct diameter discrepancy, type of the arterial and biliary reconstruction, etc.).

Comparisons can therefore be biased by these factors, which are different for each patient. However, our 

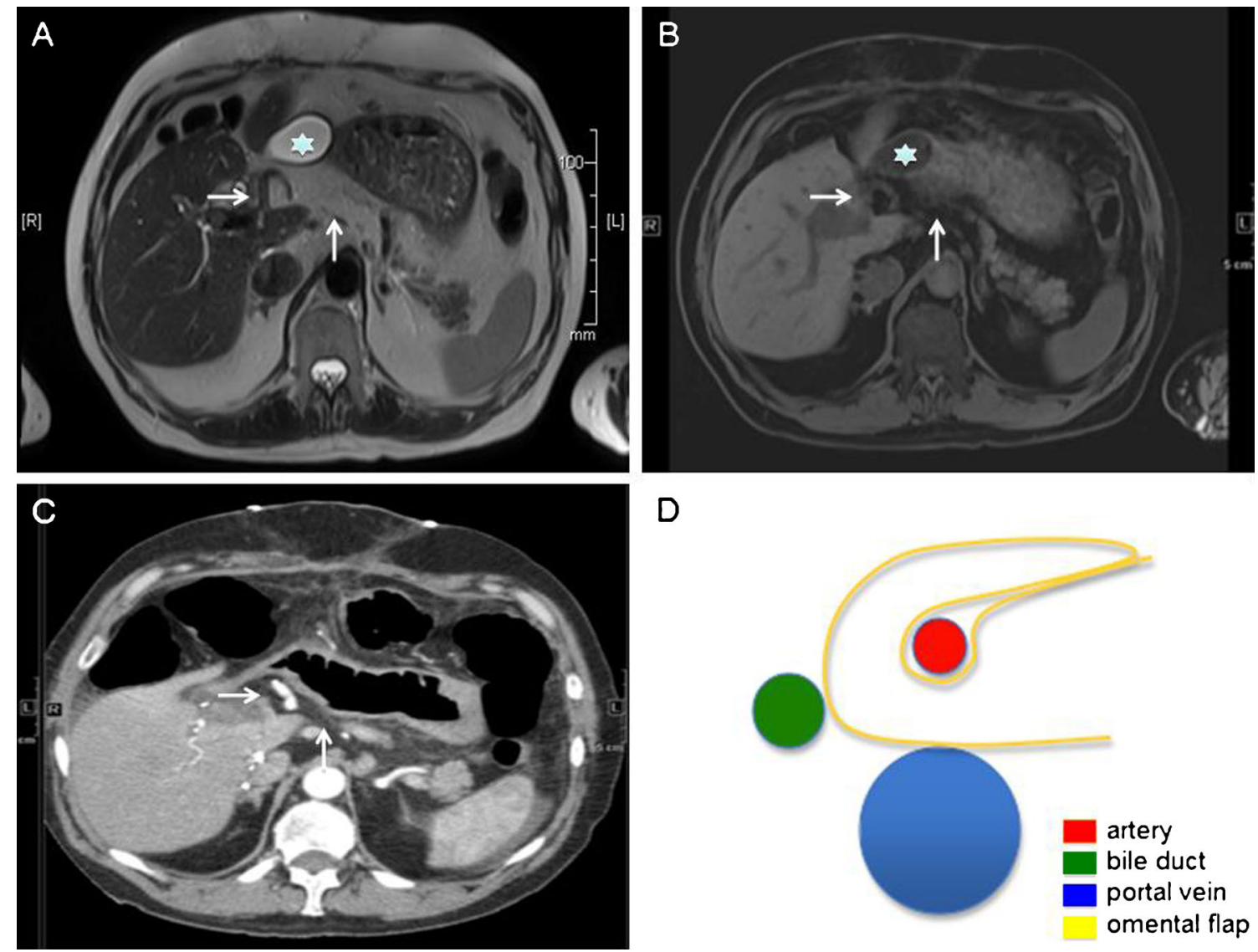

D

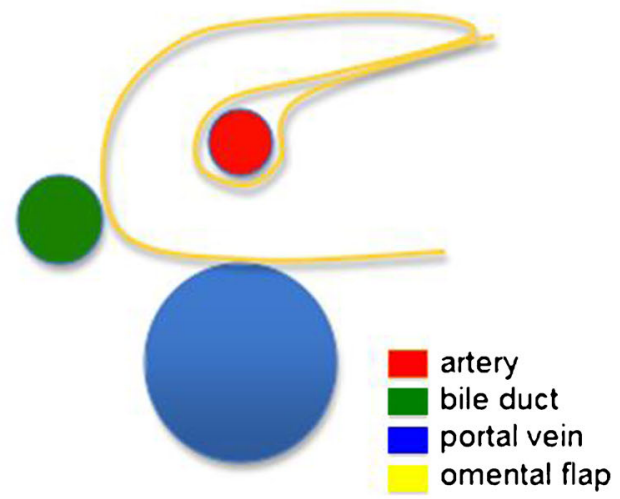

Fig. 3 Imaging (MRI (a, b), CT scan (c), and sketch (d) of the omentoplasty). Star indicates bile collection, horizontal arrow artery, and vertical arrow omental flap

technique is easy to perform and did not cause specific morbidity (omentum necrosis, hepatic pedicle compression, small bowel occlusion). Moreover, no hepatic artery complications occurred in this series, whereas 5$15 \%$ of these were reported in the literature, ${ }^{13}$ despite a "normal" rate of $\mathrm{BF},{ }^{1-3}$ suggesting the "protective" role of the greater omentum.

This technique of omentoplasty may be of interest to protect the HA, especially during LT with high donor/ recipient bile duct diameter discrepancy, which increases the risk of bile leak. ${ }^{14}$ However, the great omentum is not utilizable in all patients (previous surgery, short or atrophic). In the six cases of bile duct fistula (occurring within 30 days after LT), the patients were reoperated without special difficulties in dissecting the hepatic pedicle and performing a Roux-en-Y hepaticojejunostomy. In fact, our policy is to perform a hepaticojejunostomy if the biliary leak occurs within 30 days after LT. After the first month, an endoscopic retrograde cholangiography with sphincterotomy and stent placement is always attempted first.

Moreover, the omentum coverage reduces the risk of direct hepatic artery wall injuries during the bile duct dissection (blunt or electric dissection).
In conclusion, the omental flap coverage is an easy technique that seems to reduce the rate of hepatic artery complications after LT. A large randomized study is needed to confirm the efficacy of this technique.

Funding The authors have declared no funding.

Conflict of Interest The authors have declared no conflict of interest.

\section{References}

1. Ayoub WS, Esquivel CO, Martin P. Biliary complications following liver transplantation. Dig Dis Sci. 2010 ;55(6):1540-6. doi: 10.1007/ s10620-010-1217-2.

2. López-Andújar R, Orón EM, Carregnato AF, Suárez FV, Herraiz AM, Rodríguez FS, Carbó JJ, Ibars EP, Sos JE, Suárez AR, Castillo MP, Pallardó JM, De Juan Burgueño M. T-tube or no T-tube in cadaveric orthotopic liver transplantation: the eternal dilemma: results of a prospective and randomized clinical trial. Ann Surg. 2013; 258(1):21-9.

3. Welling TH, Heidt DG, Englesbe MJ, Magee JC, Sung RS, Campbell DA, Punch JD, Pelletier SJ. Biliary complications following liver transplantation in the model for end-stage liver disease era: effect of donor, recipient, and technical factors. Liver Transpl. 2008; 14(1): 73-80. 
4. Panaro F, Miggino M, Bouyabrine H, Carabalona JP, Berthet JP, Canaud L, Nougaret S, Ramos J, Navarro F. Reversed Saphenous Bypass for Hepatic Artery Pseudoaneurysm After Liver Transplantation. Ann Vasc Surg. 2013 Aug 21. doi:pii: S08905096(13)00236-7. 10.1016/j.avsg.2013.01.007.

5. Moriura S, Ikeda S, Ikezawa T, Naiki K. The inclusion of an omental flap in pancreaticoduodenectomy. Surg Today 1994;24:940-1.

6. Kurosaki I, Hatekeyama K. Omental wrapping of skeletonized major vessels after pancreaticoduodenectomy. Int Surg 2004;89:90-4.

7. Maeda E, Ebata T, Kanemoto H, et al. Omental flap in pancreaticoduodenectomy for protection of splanchnic vessels. World J Surg 2005;29:1122-6.

8. Sakamoto Y, Shimada K, Esaki M, Kajiwara T, Sano T, Kosuge T. Wrapping the stump of the gastroduodenal artery using the falciform ligament during pancreaticoduodenectomy. J Am Coll Surg 2007;204:334-6.

9. Turrini O, Delpero JR. Omental flap for vessel coverage during pancreaticoduodenectomy: A modified technique. J Visc Surg 2009; 146:545-548.
10. Ye QF, Niu Y, She XG, Ming YZ, Cheng K, Ma Y, Ren ZH. Pedicled greater omentum flap for preventing bile leak in liver transplantation patients with poor biliary tract conditions. Hepatobiliary Pancreat Dis Int. 2007; 6(5):470-3.

11. Starzl TE, Marchioro TL, Vonkaulla KN, Hermann G, Brittain RS, Waddell WR. Homotransplantation of the liver in humans. Surg Gynecol Obstet. 1963; 117:659-76.

12. Panaro F, Bouyabrine H, Carabalona JP, Marchand JP, Jaber S, Navarro F. Hepatic artery kinking during liver transplantation: survey and prospective intraoperative flow measurement. J Gastrointest Surg. 2012; 16(8):1524-30. doi: 10.1007/s11605-012-1897-3.

13. Saad WE. Management of nonocclusive hepatic artery complications after liver transplantation. Tech Vasc Interv Radiol. 2007; 10(3):22132

14. Panaro F, Glaise A, Miggino M, Bouyabrine H, Carabalona J, Gallix B, Navarro F. Rubber transcystic drainage reduces the post-removal biliary complications in liver transplantation: a matched case-control study. Langenbecks Arch Surg. 2013 Jan;398(1):169-76. doi: 10. 1007/s00423-012-0970-4. Epub 2012 Jun 21. 